\title{
Physicians' circularity in health regions in Brazil
}

Paulo Henrique Seixas 1

Liza Yurie Teruya Uchimura 2

Ana Luiza d'Ávila Viana 3

Rodrigo Calado da Silva 4

1,4 Faculdade de Ciências Médicas da Santa Casa de São Paulo. São Paulo, SP, Brasil.

2,3 Departamento de Medicina Preventiva. Faculdade de Medicina. Universidade de São Paulo. Av. Dr. Arnaldo, $4552^{\circ}$ andar. São Paulo, SP, Brasil. CEP: 01.246-903.

E-mail: lytuchimura@gmail.com

\begin{abstract}
Objectives: to characterize the medical circularity in Brazil and to discuss the case in the North and South Barretos regions, São Paulo.

Methods: a cross-sectional study using secondary data from the national registrations and a case study of physician's sample in the North-Barretos and South-Barretos regions.

Results: in the health regions in Brazil, on an average, $45 \%$ of the physicians in activities circulate in more than one region. The Capitals of the States have more stable physicians while more than $50 \%$ of the medical workforce work in other regions. The professionals with the greatest tendency to move from one work place to another are those who work in surgical specialties in services to uphold the diagnostic and therapy.

Conclusions: there is a high circulation of physicians among the regions, with distinct characteristics between geographical and health regions. In case of Barretos area, the professionals move from one workplace to another according to their professional association and specialized practice.
\end{abstract}

Key words Distribution of physicians, Regional, Health system 


\section{Introduction}

The dynamics of the health systems is evident when we observe the health professionals moving from one workplace to another and the flow of patients. The issue on the professional's mobility is being addressed under different aspects. One of the first discussions about this was presented by Sturdavant and Jydstrup in 1955, apud Campos and Manlik, 1 who analyzed the difficulty of setting a nursing staff at a hospital in the United States to offer healthcare.

The physician's mobility has been observed since 1940 , especially with the migration of these professionals in the dynamics in the European territory. Costigliola ${ }^{2}$ reported that the medical professionals' migration is basically related to the health system problems and that this is not a fundamental problem on the system itself, but a problem that the managers need to identify it not as an isolated symptom. For the author, the positive side of this mobility occurs when it is temporary and with intentions to expand knowledge with benefits for the patients. However, if the mobility occurs in the long term, the negative impacts occur with the financial loss of the Country that has invested in physicians' education on healthcare system that would expand the contigent of lack of physicians or bad distribution and, consequently, for the patients' access. ${ }^{2}$

Other authors 3,4 claim that urban areas are more attractive to the health professionals due to social, cultural advantages and even their own facilities that no other profession could offer. In addition, reinforcing the advantages for better opportunities to progress in the career, job prospects and wide access for the private component of health, this is an important item in low and medium socioeconomic development Countries. 3,4

A study in Portugal revealed that multiple jobs among nurses and physicians were a relevant factor in the health system. The multiplicity was considered as "a situation in which a health professional keeps several positions related to health in different work contexts, either public or private". The medical professionals present a greater multiplicity than the nurses. And, the family physicians were considered as the professional group with the highest prevalence of multiple jobs. Furthermore, the criterion with the highest relevance to work in the private sector for the physicians was professional autonomy. ${ }^{5}$

Frequently, this diversity of job links associated to the physicians' relocation in his/her area of expertise, appears as a negative characteristic of practice, related to the professionals' weariness, or a low quality care is justified as a response by a profes- sional in receiving a low salary payment. ${ }^{6}$

Another mobility observed was the medical professionals' turnover defined as the "professionals' float" expressed in the relation between admissions and dismissals of professionals hired, occurring on a voluntary basis or not, in a period of time. ${ }^{7}$ Some studies suggest that the greatest physicians' turnover occurs in the South and Southeast regional, higher than the national average $(36.7 \%) .{ }^{8}$ Campos and Malik ${ }^{1}$ reported that the turnover rate above $26 \%$ is considered bearable even by causing financial impacts on the organization of the system. These authors also affirm that an index above 50\% presents risks in the quality and productivity of the health services.

The human resources in health are considered essential elements in reducing access barriers for the Rede de Atenção à Saúde (RAS) (Healthcare Network). In relation to the physicians, they are considered as the main problems in the shortage of these professionals and also, the poor geographical distribution, especially for the medical specialists among the geographical areas and the different levels of care. Some studies suggest specifically in primary care, that the physicians' availability could overcome if the turnover problems were solved. 9

The implementation of the regional and integrated health systems, in order to overcome the divergence between the situational diagnosis with the increase of chronic diseases and with the current health initiatives aiming for acute pathologies, resulted in the creation of RAS in Brazil, in which demanded the establishment of autonomous partnerships, but interdependent, between Cities and States. 10 RAS was defined as an arrangement of organizational actions and health services in different densities of technology, integrated by means of technical support, logistical and management systems. ${ }^{11}$

When effectively designed and implemented, the regionalization allows a health system to coordinate care, eliminate redundancies, reduce costs, optimize resource utilization and improve the results.

A study conducted with managers in Canada observed a weak involvement of physicians with the health system and especially with the issue of regionalization. The physicians' modes of involvement, recruitment and salary payment were recognized by the participants in the study as one of the biggest obstacles to improve the performance of the regional health systems in Canada. 12 In this perspective, the physicians' involvement is an essential factor to obtain a full implementation of regionalization in health services. 13 


\section{Physicians' Circularity and Regionalization}

All the different approaches regarding the professionals' mobility - migration, turnover, multiplicity/diverse job links, these bring important elements to discussion on two fundamental problems for the structuring of health systems distribution/availability of professionals and regionalization. What is intended here is to adjust this prospect of medical moving from one workplace to another for a new approach: verify how professionals move around the Country and, more specifically, within and among regions, and from the description of complexity of these movements in analyzing them in a more integrated process of structuring health regions. Such observation will enable us to identify whether there are in fact professionals with characteristics of regional practice.

We chose to call this type of mobility as medical circularity defined by the professional physicians' diversity of constituents job links in their daily work, which occurs over a certain period in certain geographic spaces. 7 This differs from the concept of migration to the extent in which relates to changes more definitive including moving from one workplace to another, while this refers to the mobility between services and regions that are performed daily of the professional's work, therefore it repeats itself cyclically. On the other hand, it considers and complements the concept of the diversity of job links to the extent that applies to all the physicians or specialists in that region, in relation to other regions where these professionals could work.

Often the solution to deal with the problem of diverse of job links would be the professional's job link in one or a few services associated to a more stable work and with a more adequate salary - sometimes is understood as with a propose to create a better career. ${ }^{14}$ If this may be an important strategy for the professional's performance in the family health then this does not always apply in their work and in various other specialties, where the setting could be a strategy not only unproductive, but inefficient.

Thus, this study proposes to introduce the discussion about how this mobility is associated to different determinants - demographic factors, assistance structure, possibilities of access - as well as with the regional job market, and what limit is the local productive arrangement as well as the ordination determines or influences this circularity and is related to such interests; what is the impact in terms of the population's access to the public health services and, finally, what is the possibility of the
State officials interfere in this mobility as a positive way.

The objective of this study is to scale the medical circularity in the health regions of this Country deepening some of the aspects when discussing the case of the North-Barretos and South-Barretos regions in São Paulo, Brazil.

Thus, even though the background theme is not original - physicians' migration, professionals' availability, strategies for attraction and setting - the approach, inserting the regional discussion of circularity as a constituent factor of this availability and identifying patterns and factors related to these mobility, seeking to denaturalize this phenomenon in order to allow redistributive interventions and public policies to be more efficient. However, this more integrated approach is not very much observed in the national and international literature which limited a little the dialog with other experiences.

\section{Methods}

\section{Medical circularity}

This is a study that contemplate two complementary strategies: a cross-sectional study seeking to identify patterns of medical mobility among the regions in this Country, created through the use of secondary data from the national data sources, associated to a case study in a health region, whereas seeking deeper description of the productive arrangement of the local health and the implications of this circularity, therefore, observed.

This cross sectional study used data from the Cadastro Nacional de Estabelecimentos de Saúde (CNES) (National Registration of Health Establishments) works with Departamento de Informática do Sistema Único de Saúde (DATASUS) (Information Department of the Public Health System). This study is part of a research "Politica, Planejamento e Gestão das Regiões e Redes de Atenção à Saúde no Brasil" (Policy, Planning and Management of the regions and networks in Health Care in Brazil), which the main objective is to identify the conditions that are in favor or hindering the regionalization in the States and the conformation of the healthcare networks understanding the possible barriers to reduce inequality in the universe of health in Brazil.

438 health regions were selected in Brazil in March 2013 to March 2014 for all medical professionals registered at the national basis during this period.

Two groupings were constituted for the analysis of the physicians' mobility: - stable and non-stable- 
which remained working in the region over a certain period of time - March 2013 to March 2014, which allows an approximation with the capacity to retain professionals over time; - exclusive and non- exclusive professionals - percentage of professionals who work exclusively or not in this region - also enabling considerations about the dependence of medical work in this region in relation to other.

These categorizations allow two types of observations - one is directed to the regions - as these organize the mobility of its professionals internally and in relation to other regions. Thus, it would be possible to identify regions with inter and intraregional circulation patterns, its dependence on external works and its capacity to withhold. And the second approach is aimed to the professionals - how they circulate and are linked to the services in different regions, eventually, allowing to identify any patterns or profiles of the physicians' mobility and their specialties - how and where they work and are linked to exclusive and non-exclusive jobs and with what skills.

The data were treated and reviewed in a semiautomatic form and manually checked for consistency and integrity. They were filtered based on the Classificação Brasileira de Ocupações (CBO, version on 05/03/2010) (Brazilian Classification of Occupations,) with the selection on all medical occupations. For the calculations involving demographic densities, the estimates of the resident in the cities were used as a reference date on $07 / 01 / 2014$, and were obtained from the statistics database from the Instituto Brasileiro de Geografia e Estatística (IBGE) (Brazilian Institute of Geography and Statistics). The processing and data analysis were performed by using the environment $\mathrm{R}$ programming (v.3.1.1). As measurement summary, we chose mean, standard deviation, median and maximum and minimum values. The source code of the programs developed is available in the research site and contains the necessary documentation to reproduce the results upon request by the coordination's authorization. The maps were generated from the State supplied by the division of Geociencias do IBGE (IBGE Geosciences) using ArcGIS (v10.0) and Quantum GIS (v2.8.1) programs.

\section{Case study}

The case study is an empirical inquiry that investigates a contemporary phenomenon within a real life context, when the border between the phenomenon and the context is not clearly evident and where multiple sources of evidence are used. The multiple sources of evidence allow to strengthen the validity of the case study construct and could provide multiple assessments of the same phenomenon that seeks to corroborate the same discovery, a development of converging research lines. 15

Thus, the case study should enable to associate observations regarding the physicians' circularity in the region with characteristics of the local health productive process, whereas job market, hiring agents, the main forms of linking agent trainers, corporate organization, mix private public, professional profiles and professional exercise, working strategies that could understand and possibly influence these mobility.

Thus, a case study was performed with physicians and managers in the North-Barretos and SouthBarretos regions in the Southeast macro-region in Brazil, in August 2015. The regions were selected according to the criteria of the socioeconomic development and offering/complexity of health services, along with the typology of regions proposed by Viana et al.16 These regions were selected in the national study in order to understand the multiple influences of the physicians' circularity in these health regions, in which presents better scores of the authors' typology of the regions.

11 physicians from the North-Barretos and South-Barretos regions were interviewed and the managers of the main regional services. According to the inclusion criteria, every physician should have at least a medical residency and at least one employment job, whether it is public or private. Data from CNES were used to identify and locate physicians. The medical professionals were selected to ensure specialization diversity of skills, number and types of job links, service diversity and age, in different cities of the region. Everyone authorized the interview and audio recording.

A specific guideline for the professionals was elaborated with six open questions related to working hours and workplaces, determined elements for choosing the workplaces, working individually or in groups, working in another medical specialization and information about the professional registration at CNES.

The study was approved by the Ethics Committee of the Faculdade de Medicina da Universidade de São Paulo, process number 071/15, and according to the Conselho Nacional de Saúde (National Health Council) norms 466/12.

\section{Results}

The study analyzed 332,830 physicians who presented an average of 2.9 job links per 
professional. The average of non-exclusive is $36.34 \%$ in Brazil (a percentual of physicians with job links in more than one region in the country) and the average of non-exclusive in the regions is $44.56 \%$. Our study identified that physicians go beyond the health regions borders, in other words, the inter-regional moving from one workplace to another was intense, approximately $35 \%$ to $40 \%$.

The data allowed to demonstrate that there are professional groups confined in one region, they are called stable physicians with a high stability in some regions in the Country, as it is the case in the metropolitan regions of the Northeast, Midwest, Southeast and South.

In March 2014, the health region with the highest number of non-exclusive physicians with job links in more than one region was the $26^{\text {th }}$ region in Rio Grande do Sul and the lowest was in Campo Grande region. When comparing the period of 2013 and 2014, an average reduction was observed, 1.5\% in the number of physicians with exclusive job links in the focused region (exclusive physicians). We identified the variation of exclusive medical professionals in the regions, each region conceded about $5.7 \%$ of their physicians to other regions, while the region received other $4.2 \%$ not necessarily exclusive.

Considering the large geographic regions (North, Northeast, Midwest, Southeast and South) and the health regions in the Country, the non- exclusive medical professionals which circulate in other regions, present a quite distinct dynamic (Figure 1). In the Northeast, the average of physicians circulating in the health regions was the highest in the Country (54.1\%), varying with the lower rates, such as in Piauí (39\%) and higher in other places as in Alagoas (63.6\%), Paraíba (66.3\%) and Sergipe $(68.4 \%)$. The States in the North and Midwest, the circulation profile was lower compared with the Northeast macro-region, $32.9 \%$ and $34.8 \%$, respectively. We emphasize the regions Entorno in Manaus (11\%) and a wide range which crosses Mato Grosso (30\% of physicians circulating) and Mato Grosso do Sul (22\% to $29.9 \%$ ), which becomes higher in the regions closer to Distrito Federal and Goiás.

In the Southeast macro-region $(46.1 \%)$ the percentage of regional circulating professionals were higher in the metropolitan regions. In the more central areas in the countryside of the States, there was a mixed pattern in the regions with the participation of physicians circulating higher interspersed with others with regional pole characteristics of lower participation. In São Paulo city (which constitutes only one region), presents a low participation of circulating professionals (34\%) and is surrounded by five other regions with higher rates of circulating - Rota dos Bandeirantes (70.3\%), Mananciais (76.7\%), Franco da Rocha (80.5\%), Alto

\section{Figure 1}

Percentage of non-exclusive physicians by regions in Brazil, 2013 to 2014.

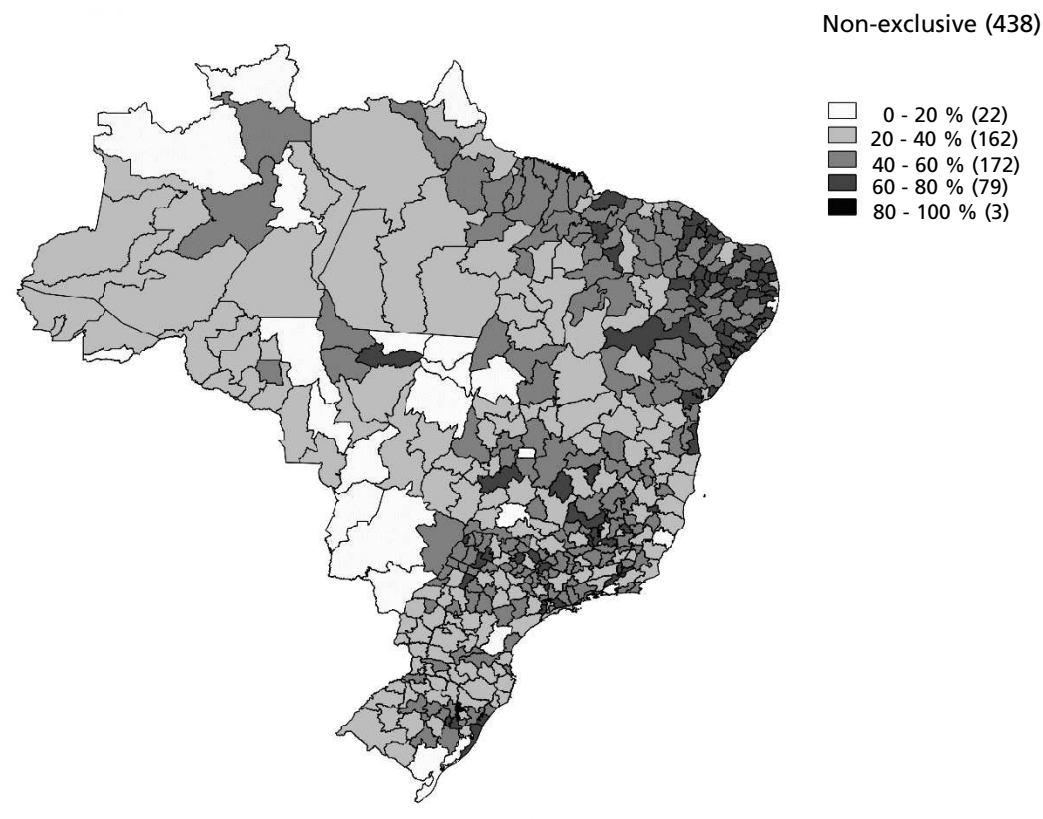


do Tietê (61.7\%), and Grande ABC (55.8\%).

The South macro-region $(38.1 \%)$ repeats the concentration of the non-exclusive pattern around the metropolitan regions. There was a high circulation in the metropolitan region of Porto Alegre, raising the rate for Rio Grande do Sul (43.2\%), while Santa Catarina (33.4\%) and Paraná $(34.6 \%)$ present lower circulation patterns. Thus, in a national panorama there was a significant participation of non-exclusive professionals, concentrated around the biggest urban centers, of being the most reduced in the regions because of the great difficulty to have access to.

\section{North-Barretos and South-Barretos Case}

According to CNES in 2015, 1218 physicians were registered in the regions of the study, $63.3 \%$ of them had a job link in Barretos city, followed by $15.9 \%$ in Bebedouro city. The region presents a high participation of non-exclusive physicians (46.9\%), this is a characteristic in regions with easy access and high economic dynamism. In Figure 2, we will show the percentage of exclusive and non-exclusive physicians in the cities of the study regions (Figure 2).

It is also possible to observe that the nonexclusive professionals tend to work more as compared to the exclusive, in occupations related to Especialidades Cirúrgicas e Especialidades de Medicina Diagnostica e Terapêtica (Surgical and Medical Specializations of Diagnose and Therapeutics), while the exclusive physicians work more in general areas and Specialized Clinics (Figure 3).

In relation to the city of main work, with the exception of service providers (Nephrologists) and the professionals linked to the Fundação Pio XII (surgical oncology), all of them confirmed that they did not have only one working place. All the interviewees had homes and families in the region. Only $36 \%$ of the interviewees work in only one health region. The remainder worked in more than one health region, whereas these other $36 \%$ worked in the South of Minas Gerais State.

In the North-Barretos and South-Barretos regions there were a large number of professionals in various activities, especially working in different specialized area than those they were specialized in, or in those areas they worked the most. Despite this, they reported that they tried not to take risks in relation to the procedures. These professionals present a high hourly workload and a large weekly shifting around from one place to another. For these professionals, working in a region without a Medical College, the option for a working location has a strong relation with the city of origin and a proximity location for medical residency, but even less for a College location.

The interviewed physicians were organized in a direct contact network - shift groups on Whatsapp with information on cooperatives activities, contest vacancies, division of work with the health plans. All the interviewees were assertive to say that they work more than 60 hours weekly.

Among the determinants in relation to work in more than one city, was related to: the salary, the recognition from the institution where they work and to obtain contacts in the cities of origin. All the interviewees have at least two formal job links. Some cities are notorious for having shifts considered in being calm (Altair, Cajobi) and other troublesome (Bebedouro, Olímpia). The interviewees' salary pattern were very similar and comparable to the medical professionals administered by the Fundação Pio XII, located in the Barretos City (R\$ $18,000.00$ to $30,000.00$ per month), although for some professionals in Pio XII, this amount has been obtained through an only one job link, while for others it was related to two or more job links.

According to the interviewees, for the shift professionals and the physicians at the Fundação Pio XII, the hiring would occur individually through a contract by a legal individual, while for the specialists in Nephrology, the hiring was in group through a mutual company. Even though it has not been possible to interview anesthesiologists, we observed through secondary data at the CNES, that a group of these professionals worked in an articulate manner in different services in the region. The interviewed shirt professionals reported working more than it is registered at the CNES, whose registration control was performed by the working company.

The Cooperative Medical services in Bebedouro appeared as a very relevant agent whose work was delimited to the South-Barretos region. The articulation of the cooperative reached approximately $70 \%$ of physicians in the region and was able to make the Santa Casa (General Hospital) from Bebedouro to stop working with SUS, working full-time with supplementary health segment. Considering the low complexity of the local City Hospital, the SUS dependent population of the most important city in the region sought higher complexity assistance outside the city. The cooperative worked primarily with the members, but 
hired physicians that were not members of the cooperative to have shifts, as they were not willing to pay the local membership fee. On the other hand, the manager of the cooperative reported the difficulty to organize a healthcare system with greater continuity, in function of little interest mainly from newer professionals, to build medical offices within the cooperative structure, (in which has been trying to organize a Medical and Diagnostic Center in the city), which they prefer to continue working shifts.

\section{Discussion}

In the health regions of the Country where there are great distances and difficulties to access, these seem to be important limitation for professionals' circulation presenting the lowest percentages of nonexclusive professionals in some national regions, such as the Midwest and the North. In the more central areas in the countryside of the States, there is a mixed pattern of regions with the participation of professionals circulating at the highest interspersed of others with regional pole characteristics with less participation enhancing these professionals attraction to urban areas confirmed by other studies. ${ }^{3,4}$ Despite of all the actions developed in the human resources area in health, these are not being sufficient, because there are empty assistance, especially in remote areas located in the North and Northeast regions. 17

The concern with the distribution of health professionals, particularly physicians, as well as the implementation of actions to facilitate facing situations such as scarcity and inequalities in the population's access to the health services have been the tone in the human resources policies to SUS in recent years. 18 The adoption of the Law number 12,871 , in 2013, that establishes and regulates the Programa Mais Médicos (More Physicians Program) in Brazil is the result of a broad political debate that has been established in the Country according to the theme and that, without definitively resolving the issue, provides important guidelines for human resources policy over the coming years. 19

As for the interviewed physicians, many of them who work shifts, work on the network, including the use of social networks in order to find job opportunities. In this case, if they are working on the network then they are capable to perform some kind

Figure 2

Percentage of exclusive and non-exclusive physicians in the cities of the North-Barretos and South-Barretos regions, 2015.

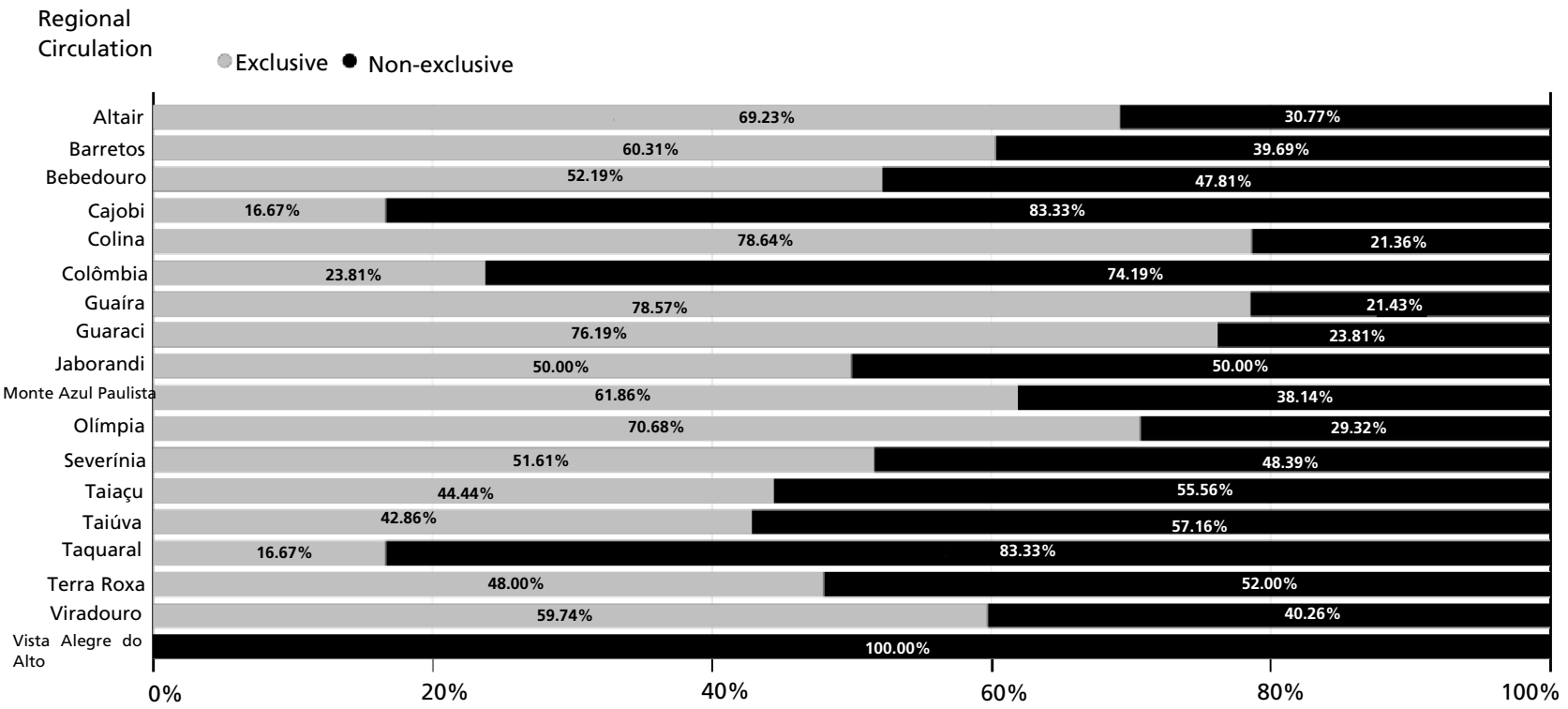




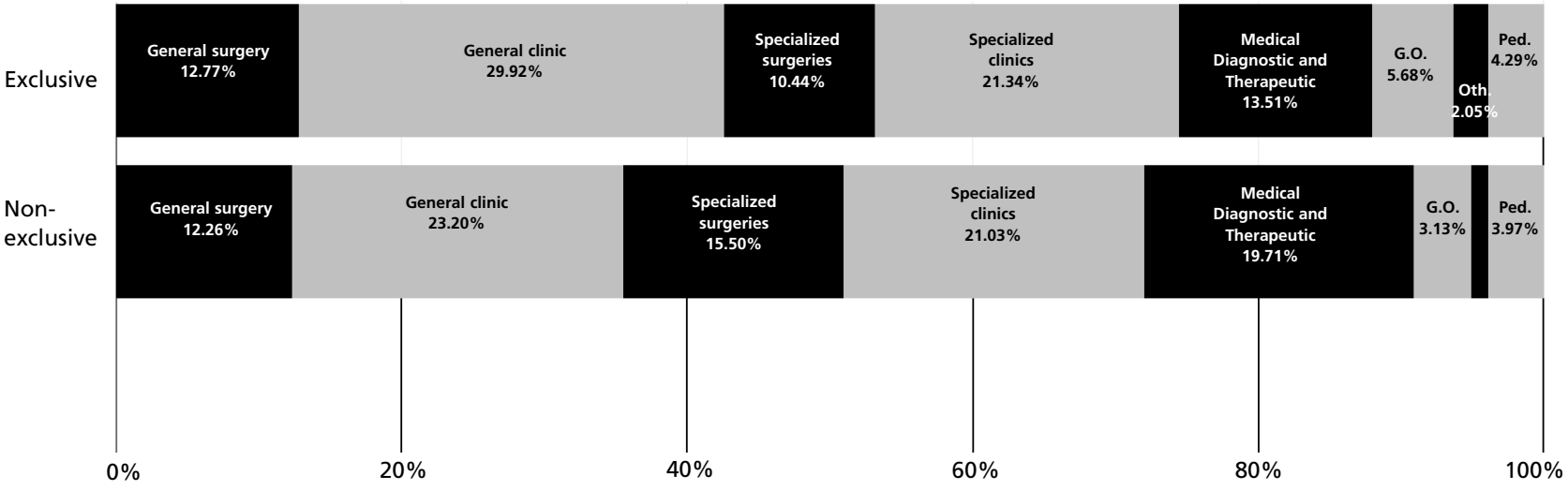

$\mathrm{CBO}=$ Classificação Brasileira de Ocupações (Brazilian Classification of Occupations); G.O.= Gynaecology and Obstetrics; Oth.= Others specialities; Ped.= Pediatrics.

of pressure on the job market, or at least permits a more intense information and therefore, the job market can show more transparency.

This study identified some patterns of circulation among physicians. First, in relation to individual providers, who work alone, selling their services and workforce seeking for shifts in different services through their networks of relationships and personal effort - In general this was a circulation that may be more intense in terms of job links, but more restricted in the possibilities of individual's moving from one workplace to another. These professionals tend to present a less specialized profile and act as individual providers tending to have a radius of less action. These are the professionals who tend to be more exclusive regionally. 7,8

In the second pattern, there were groups or medical companies - small groups, organized cooperatives or medical companies, more or less informal that organized themselves seeking to assume certain service segments at the health units ICU Pediatric, the emergency room and obstetrics. Some were more structured, as for example, the nephrology and hemodialysis companies, the radiology services and of course, the anesthesiologists' cooperatives. These in general presented a higher power of pressure and negotiation and eventually could cover more extensive regions in search of these markets. This more specialized profile and with a more entrepreneurial organization - which can be varied - tending to present a less exclusive working profile data of the professionals from Barretos.

And the third pattern identified are the entrepreneurial organizations - in this case, it could be employers working in different regions that could define physicians' moving from one workplace to another that worked according to their needs Fundação Pio XII; medical service providers that intermediated hiring workforce into service segments or assumed the direct management of various institutions. In this case, the situation depends very much on the employer's profile. Thus, several professionals working at the Fundação Pio XII worked in other Federative Units in the Country too. However, this was not a rule for all professionals. Another experience is the one related to companies that work in management actions in public services as a third party. Some of these begin to form strategies to capture external professionals to allocate them in the regions required Organizações Sociais de Saúde (Social Health 
Organizations), for example, tending to work with a mixed profile, with local acquisition and transferring some specific professionals, but they work as circulating inducers.

The best knowledge on how these different segments work and their behaviors and expectations can give the public agents a greater capacity to negotiate and interlocution and hiring different agents. In the case of the studied regions, it was possible to identify, besides the intense mobility of the professionals on shift, two very significant mobility related to public intervention in management.

On the one hand, in Bebedouro, an organized action of medical corporation ahead of the fragility or task division with local SUS managers in allowing the Santa Casa Hospital, built by the community, left SUS in the 1990s and was appropriated by the medical cooperative in 2007 , limiting its public use and population access to services of greater complexity.

On the other hand, in Barretos, the association between the Fundação PioXII and the central instance of the State Secretary of Health in the implantation of the Ambulatório Médico de Especialidades (AME) (Specialized Medical Ambulatory) allowed to have an effective and significant incorporation and attracting new specialized professionals for a region, in contrast for example, with exclusive local professionals working at the Ambulatório de Especialidades do Municipio (Specialized Ambulatory of the City), or in the Santa Casa - observable data through the CNES - the place of residence and place for professionals to work Such an association enables to implant AME, it will increase the offering of the supple complexity of services in the region, and on the other, it tends to strengthen the Fundação Pio XII comparing to other agents, up to a point that it would seek to work on the professional's qualification in primary care (matrix-based strategies) to improve in going to AMEs, as well as it strengthens its project in implanting a Medical College and its influence on the Santa Casa management. At least, until the most recent funding crisis.

Thus, this successful process, while the public intervention of implanting services, does not necessarily represent a greater balance or integration with the local health system, a task that may even be inclusive if it complicates of the imbalanced power between the agents, but that brings a great potential to qualify the public health action in the region.

\section{Conclusion}

Our study has concluded that the boundaries of the health regions in Brazil are not limiting for the professionals to move from one workplace to another. Its dimension is quite significant and brings important challenges for its management. For the cities that are not regional poles, these circulating professionals constitute many times an essential component for the medical workforce location. On the other hand, stable and exclusive physicians are the pre-requisite for the existence of regional professional and to work in fundamental segments in the organization of a local care. Soon, in a large area in the Country, it is expected to have a considerable number of these professionals.

On the other hand it is possible to characterize some patterns of regional circularity - concentration and greater stability in the Capital Cities and regional centers, the largest surrounding circulation in the regions. Less circulation in regions with difficult access or wide extension, better circulation in regions with easy access and greater economic dynamism.

It is also possible to identify some circulation modalities from the agents' perspective - individual, in group and organizational, identifying how to constitute these mobility, as well as, in what groups - of the physicians, the specialized, or the institutional agents act in these processes in different realities in this Country.

This knowledge, nowadays it is more empirical among those involved in its direct negotiation, it can help to structure redistributive public policies to become better structured and negotiated.

The results of our study add strength to other works on human resources in health, in order that, managers and health system providers to identify the diagnosis of the medical circularity for a better planning in the health policies. In addition, we reinforce the lack of trained medical professionals working in the regional area.

This study presented a limitation of a nonidentified circulation of the patients along with their physicians. In addition, we highlight the limitations of the national data bank in the processes of more recent job links and the dependency of the information on the physicians' data manipulation in relation to the employer. 


\section{References}

1. Campos CVDA, Malik AM. Satisfação no Trabalho e Rotatividade dos Médicos do Programa de Saúde da Família do Município de São Paulo. Rev Adm Pública. 2008; 42 (2): 347-68.

2. Costigliola V. Mobility of medical doctors in cross-border healthcare. EPMA J. 2011; 2 (4): 333-9.

3. Van Lerberghe W, Ferrinho P, Conceição C, Van Damme W: When staff is underpaid: dealing with the individual coping strate- gies of health personnel. Bull World Health Org. 2002; 80: 7581-4.

4. Dussault G, Franceschini MC. Not enough there, too many here: understanding geographical imbalances in the distribution of the health workforce. Hum Resour Health. 2006; 4 (1): 12 .

5. Ferrinho P, Biscaia A, Fronteira I, Hipólito F, Dussault G Multiple employment in health sector in Portugal. Cah Sociol Demogr Med. 2007; 47 (3): 331-46.

6. Sales TB, Andrade MA, LunaII AP, FeitosaII LB. Multiplicidade de vínculos de médicos no Estado do Ceará. Rev Saúde Pública. 2011; 44 (5): 950-6.

7. Seixas PHD, Silvestre D de AMM, Viana ALD, Uchimura LYT, Pereira APC de M. Movimentação Médica no Brasil. Novos Caminhos - Nota técnica 2/15. Disponível em: http://www.resbr.net.br/wpcontent/uploads/2015/04/MovimentacaoMedica.pdf

8. Pierantoni CR, Vianna CM de M, França T, Magnago C, Rodrigues MP da S. Rotatividade da força de trabalho médica no Brasil. Saúde em Debate. 2015; 39 (106): 637 47.

9. Oliveira APC de, Gabriel M, Poz MRD, Dussault G. Desafios para assegurar a disponibilidade e acessibilidade à assistência médica no Sistema Único de Saúde. Ciên Saúde Coletiva. 2017; 22 (4): 1165-80.

10. Guerra DM. Descentralização e Regionalização da Assistência à Saúde no Estado de São Paulo: Uma análise do Índice de Dependência [tese]. São Paulo: Faculdade de Saúde Pública da Universidade de São Paulo; 2015.

11. Brasil. Presidência da República. Ministério da Saúde. Portaria $\mathrm{n}^{\circ} 4.279$, de 30 de dezembro de 2010. Estabelece diretrizes para a organização da Rede de Atenção à Saúde no âmbito do Sistema Único de Saúde (SUS). Diário Oficial da União, Brasília (DF), Seção 1, p. 89, 2010, 31 dez.
12. Bergevin Y, Habib B, Elicksen K, Samis S, Rochon J, Adaimé C, Boucher G, Denis JL, Roy D. Towards the Triple Aim of Better Health, Better Care and Better Value for Canadians: transforming regions into high performing health systems. Canada: Canadian Foundation for Health Improvement; 2016. Disponível em: https://www.cahspr.ca/web/uploads/conference/2016-0331_Regionalization_Report.pdf

13. Fink J. Aligning with physicians to regionalize services. Healthc Financ Manage. 2014; 68 (11): 80-6.

14. WHO (World Health Organization). Increasing access to health workers in remote and rural areas through improved retention: global policy recommendations; 2010.

15. Yin RK. Estudo de caso: planejamento e métodos. 5 ed. Porto Alegre: Bookman; 2015.

16. Viana ALD, Bousquat A, Pereira APCM, Uchimura LYT, Albuquerque MV, Mota PHS, Demarzo MMP, Ferreira MP. Tipologia das Regiões de Saúde: condicionantes estruturais para a regionalização no Brasil. Saúde Soc. 2015; 24 (2): 413-22.

17. Maas LWD, Girardi SN, Carvalho CL, Araújo JF, van Stralen ACS, Massote AW, Rodrogues JC, Fernandes JLC. Estudo de Levantamento de Aspectos Demográficos, de Formação e de Mercado de Trabalho das Profissões de Saúde de Nível Superior no Brasil entre 1991 e 2010. Relatório Final. Observatório de Recursos Humanos em Saúde. Estação de Pesquisa de Sinais de Mercado EPSMP, - NESCON, UFMG; 2014. [acesso em $12 \mathrm{fev}$ 2015] Disponível em: http://epsm.nescon.medicina.ufmg.br/epsm/Estudos_Pesqui sa/Mercado de trabalho das profissoes de nivel superior no Brasil (Rel.Final).pdf

18. Pierantoni CR, Varella TC, Santos MRD, França T, Garcia AC. Gestão do trabalho e da educação em saúde: recursos humanos em duas décadas do SUS; Health care work and education management in the SUS: 26 human resources in 20 years of the Unified Health System. Physis (Rio J.). 2008; 18 (4): 685-704

19. Brasil. Presidência da República. Lei n ${ }^{\circ} 12.871$, de 22 de outubro de 2013. Institui o Programa Mais Médicos, altera as Leis no 8.745 , de 9 de dezembro de 1993, e no 6.932, de 7 de julho de 1981, e dá outras providências. Diário Oficial da União, 23 de outubro de 2013.

Received on June 1, 2017

Final version presented on August 19, 2017

Approved on September 8, 2017 